\title{
Factors affecting hormonal and non hormonal contraceptive method use in women presenting to Reproductive Health Services-A Centers (RHS-A) of Karachi
}

\author{
${ }^{1}$ Dr. Zaheen Baig, ${ }^{2}$ Dr. Juanita Hatcher, ${ }^{3}$ Dr Sarah Saleem \\ ${ }^{1}$ BahriaUniversity Medical \& Dental College Department Of Community Health Sciences, ${ }^{2},{ }^{3}$ Aga Khan \\ University Department Of Community Health Sciences
}

\begin{abstract}
Fertility is an important predictor of maternal mortality: high fertility levels being associated with high maternal mortality. Factors like use of contraception, fertility preferences are empirically shown to influence fertility levels. Choosing a method of birth control, its effectiveness and safety are the key considerations.

Objectives of the study were to determine the proportion of women using hormonal and non-hormonal contraceptive methods among modern contraceptive users and to determine factors associated with use of hormonal and non-hormonal contraceptive methods.

This was a Cross sectional study conducted on women of 15-49 years of age who were continuously and consistently using a modern contraceptive method for at least last three months. Women were selected by convenient sampling technique from four family planning centers located in Karachi. Women who refused to participate or those women who had language problem were excluded from the study. Information was gathered regarding demographic and socioeconomic status, previous pregnancies, health concerns, previous knowledge of contraceptives and husband's approval.

After adjusting for other variables in the model, it was found that with every one year increase in age of women the odds of hormonal use decreased (OR 0.91; 95\% CI 0.88, 0.93). It was also found that with every one additional child in the family, the odds of hormonal use decreased (OR 0.79; 95\% CI 0.73, 0.86). Women whose husbands approved of contraception were found at lesser odds of hormonal use (OR 0.43; 95\% CI 0.25, 0.73). Women whose source of knowledge of contraceptives were family and friends were also found at decreased odds of hormonal use (OR 0.64; $95 \%$ CI 0.45, 0.92). Women with health concerns were found at elevated odds of hormonal use (OR 1.70; 95\% CI 1.32, 2.19). The hormonal user in our study is a young woman of 29 years of age, with an average of four pregnancies and same number of living children, who does not require her husband's approval for contraceptive use. Her existing knowledge of contraceptive use is influenced by family and friends who is not in favor hormonal use. She is concerned about her health related to her current contraceptive method.

Media has little role for dissemination of information regarding contraceptives.
\end{abstract}

\section{Introduction}

Pakistan is the seventh most populous country of the world with an annual growth rate of $2.6 \%$ and a total fertility rate of 4.8 (1) meaning that on an average a woman in Pakistan gives birth to five children during her entire reproductive lifetime. The unbridled population growth is attributed to young age structure and high fertility. Approximately $56.0 \%$ of the total population belongs to the young age (2). Pakistan is one of the few countries with an inverse sex ratio, for every 111 men there are 100 women (3). The main reason for this discrepancy in the statistics is due to high number of women dying during pregnancy and labor. Maternal Mortality ranges between 360 to 600 deaths per 100,000 live births in the country (4). Similarly morbidity burden is also high, about $15 \%$ of all pregnancies end up in complications having long-term and short term consequences (4). High Fertility has been identified as an important predictor of maternal mortality (5). With improvements in health and living conditions, mortality rates decline first and as development continues, fertility levels follow. This is explained by reduced need for larger families as sources of labour or social support under better socio-economic conditions. Declining infant and child mortality levels contribute to decreasing fertility as well, reducing the need for backing up the expected loss of children before they grow up (6).

A number of other factors are empirically shown to influence fertility levels. The use of contraception, fertility preferences, educational levels of women, women's status and age structure of the society are the most important determining factors (4). 
Factors affecting hormonal and non hormonal contraceptive method use in women presenting to Contraception

Contraception is defined as the prevention of conception without abstinence (7) There are traditional methods of contraception, which include withdrawal and rhythm, and there are modern contraceptive methods, which include the hormonal and non-hormonal methods. The hormonal methods include oral pills, injectables and sub dermal implants and some intrauterine contraceptive devices whereas non-hormonal contraceptives include condoms, intrauterine devices like Copper-T and sterilization (Tubal Ligation in women and vasectomy in $\operatorname{men}(8)$

\section{Global Contraceptive Prevalence}

Worldwide contraceptive prevalence (the percentage of married women currently using contraception) was estimated to be 58\% in 1993 (9), with contraceptive use in the developed regions at $70 \%$ and in the developing regions at 55\% (9). Among the developing areas, contraceptive prevalence is lowest in Africa where on average only one out of five married couples is currently using a contraceptive (9). In Asia and Latin America and the Caribbean, contraceptive use is similar. However data at the regional levels reveal greater divergence than is implied by the overall averages (9).

Modern methods account for the majority of current global contraceptive practices, almost nine out of every ten contraceptive users rely on a modern method (9). Female sterilization, intrauterine device and oral pills account for more than two-third of all contraceptive practice worldwide (9). Globally, female sterilization is the single-most used method and alone accounts for one-third of all contraceptive use worldwide (9). The IUD is used by $22 \%$ of all contraceptive users and the oral pill by $14 \%$ (9). The use of modern contraceptive method differs significantly between the developing and developed areas. In the developing areas, modern methods account for much larger share of total contraceptive use (90\%) than in the developed areas (70\%) (9). This is largely because certain traditional methods including withdrawal and various forms of the calendar rhythm method are commonly used in developed regions (9). Many women in developing countries would rather risk an unwanted pregnancy than put up with the side effects of efficient contraceptive methods (10).

In developing world about one in four married women who wants to avoid a pregnancy is not using contraception (11). Many factors contribute to this unmet need for contraception including lack of knowledge about contraception, fear of side effects, opposition from husbands, misconceptions about contraception, dissatisfaction with the methods, and poor access to or a limited choice of contraceptives (12).

The most effective contraception is sterilization, followed closely by hormone implants such as Norplant, hormone injections such as Depo Provera and the progestin only pill (13). The most effective contraception has a failure rate of less than $1 \%(13)$.

\section{Countrywide Situation of Contraception}

According to Pakistan Reproductive Health and Family Planning Survey PRHFPS (2000-01) 27.6 percent of currently married women are users of some form of contraception (14). Of these, the survey further showed that nearly a quarter of contraceptive users are sterilized (14). The most popular temporary method is condom (20\%), closely followed by withdrawal (19\%) and IUD (13\%) (14). Even though the popularity of injection and pill is rising, only $9 \%$ and $7 \%$ of current users chose these spacing methods. Nearly half (45\%) of all couples that are practicing contraception rely on methods (condom, withdrawal, periodic abstinence) that require the initiative or at least the compliance of husbands (14). Use is nearly twice as high in urban areas as in rural areas and rises strongly with level of education according to the same survey (15). The individual variation is on account of her social class, her age (9), the number of children she has, the number of pregnancies she had, her educational status (as is evident from the PRHFPS 2000-01, 46.9\% of current users of any method have secondary level education whereas only $22.2 \%$ users were not educated) $(14,16)$, and her health status.

\section{Non-hormonal methods Use of Male Condoms}

Condoms are used by $15 \%$ of couples in developed countries and only $3 \%$ in developing countries (13). Only three of hundred couples who use condoms perfectly for one year will experience an unintended pregnancy (8). Male condoms were found to be $87-96 \%$ effective in preventing HIV transmission between discordant couples when only one person is HIV infected (17). Condoms are declared preventive for HIV and STD's and there is reduced risk of gonorrhea, Chlamydia and trichomoniasis (18).

\section{Practice of Tubal ligation (TL)}

Tubal Ligation (two methods are Minilaparotomy and Laparoscopy, former being more common), a permanent method of contraception has a failure rate of $0.1 \%$ (8). Depending on the sterilization technique used, between 800 and 2000 women per 100,000 can expect a major complication at the time of operation (19). Minilaparotomy patients may suffer from such complications as infection, injury to bladder or bleeding from a major blood vessel, and burning of the bowel or other structures. There can also be anesthesia complications 
Factors affecting hormonal and non hormonal contraceptive method use in women presenting to

(20). Apart from these immediate complications of surgery post tubal complications are so frequent they are now called "Post tubal Ligation Syndrome", of which long term health risks include abdominal cramps, heavier, longer periods, dysfunctional uterine bleeding, dysparunia and pelvic pain or pressure (21). A review of the literature on post tubal Ligation problems revealed an incidence of 22 to $37 \%$ (22).

\section{Use of Intrauterine Contraceptive Devices (IUD's)}

IUDs are very effective for pregnancy prevention $(0.6$ to 0.8 pregnancies per 100 women in first year of use) (8). In the first year of use the copper IUD has a $0.5 \%$ pregnancy rate, an approximate $6 \%$ expulsion rate and a 15\% rate of removal for medical reasons (mainly bleeding and pain) (23). Asia accounts for the majority of IUD use, but is also common among married women of reproductive age in Scandinavian countries and in other European countries (7\%) (24). In contrast only $1 \%$ of women in United States use the IUD. This low rate is thought to reflect the widespread concern about health risks associated with the method. In lieu of using an IUD, women may prematurely request sterilization $(25,26)$, choose less effective or less convenient methods, or risk an unwanted pregnancy. Contemporary copper IUDs may be among the safest, most effective and least expensive reversible contraceptives available (27).

\section{Hormonal Use \\ Use of Oral Contraceptives (Pills)}

Oral contraceptive is the most popular form of contraception in American women (28). They are very effective when used correctly and consistently (6-8 pregnancies per 100 women in first 12 months of use) (8). During more than 35 years that the pill has been available, considerable resources have been applied to investigating its health effects (29). As a consequence of this research and resulting product refinements, oral contraceptives are one of the safest drugs marketed; their safety is particularly striking in comparison with the health risks posed by the pregnancies that pill use prevents (30). Side effects are widely believed to influence compliance with treatment, but the incidence of side effects in women beginning new low dose therapy with OCs is unknown (31). The most common side effects are nausea and vomiting, breakthrough bleeding and spotting, headaches, bloating or swelling and breast tenderness (31). By virtue of their ability to prevent pregnancy in $99 \%$ of women who use them properly, oral contraceptives have revolutionized reproductive choices for women.

However oral contraceptives are not a panacea. Adverse events although rare, include deep venous thrombosis, pulmonary embolism, ischemic stroke, liver cancer, and myocardial infarction among women over 35 years of age who smoke (32). Long term use of oral contraceptives may also increase the risk of cervical cancer among women with a positive test for the human papiloma virus (33). But for most women, the benefits of avoiding pregnancy, with its attendant health risks, clearly outweigh these side effects. In addition, the quality of life may be enhanced by benefits such as greater regularity of menstrual cycle, reduced menstrual blood loss and improvement of associated iron deficiency anemia and dysmenorrhea.

\section{Use of Injectable Contraceptives}

Injectable hormonal contraceptives are highly effective ( 0.3 pregnancies per 100 women in first 12 months of use) (8) and satisfactory contraceptives (34). The two main preparations available today are depot medroxy progesterone (DMPA) and Norethisterone Oenanthate (NET-OEN) (34), but several other preparations are currently under trial. Injectable contraceptives have some unique advantages which give them justifiably wide appeal amongst many groups of women (34). The common side effects are changes in menstrual bleeding, weight gain, delayed return of fertility, headaches, breast tenderness, moodiness, nausea, hair loss, less sex drive, and/or acne in some women (8).

\section{Use of Subdermal Implant (Norplant)}

One of the most promising advances in contraceptive technology has been the development of long acting contraceptive implants. Norplant (sub dermal implant is effective for five years) ( 0.1 pregnancies per 100 women in first 12 months of use) (8)has been registered in over 60 countries and about 6 million women worldwide have used Norplant (35). Common side effects include changes in menstrual bleeding, headaches, dizziness, enlargement of ovaries or ovarian cysts, breast tenderness and/or discharge, nervousness, nausea, acne or skin rash, change in appetite, weight gain, hair loss or hirsutism (8). In a prospective cohort study on Singaporean women (36), menstrual irregularity was the most common side effect and reason for early discontinuation similar to other studies $(29,37-40)$ Norplant has not been found to produce any long term adverse effects (41). In Pakistan, the social acceptance of Norplant is very high $(76 \%)$ and more than half of the users $(52.5 \%)$ are satisfied with the method (42).

\section{Contraceptive Choices and Preferences}

Contraceptive choices and use among women can vary according to a number of reasons. Her decisions not only base on her desire for birth spacing or limiting family size but also on the availability of adequate 
information, contraceptive method choices, and liberty to make her own decisions. They are then more likely to be satisfied and to continue to practice family planning (43). Other important factors contributing to contraceptive use are affordability, accessibility and secrecy for method use if desired (44).

Hormonal methods (pills, injectables or implant) are preferred by women when they desire to space childbirths yet preserve their fertility. The method, having a short effective duration fulfills this desire. On the other hand, Non hormonal methods, particularly tubal ligation, are usually chosen when there is a need for limiting family size particularly tubal ligation (45)

Method related factors for prime consideration are safety of the method, its duration of effectiveness and its reversibility (46). Although side effects influence the acceptability and continuation of hormonal contraceptives (47) but at present hormonal contraceptives are the safest method to prevent pregnancy (48).

Discontinuation rates for hormonal contraceptives, largely attributable to side effects and health concerns are high in nearly all less developed countries for which Demographic and Health Survey Data are available (13).

Satisfied clients are more likely to use contraception consistently and correctly (49), confirmed by a study wherein $40-70 \%$ of developing world users abandons use of oral contraceptives within 2 years because of side effects (10). An additional 25-33\% of women do not use contraceptives at all because of a fear of side effects (10).

Secrecy of use of a contraceptive method is also a prime consideration for many women particularly in Pakistan and India (9). Hormonal methods particularly pills and injectables have the added advantage where they can be used by women secretly, without anyone's knowledge, whereas tubal ligation being a permanent method cannot be secretly opted for.

Couple's agreement over choice of contraceptive method is not only important because of husbands needed compliance for some methods but also because family planning is an equally important concern for a husband as it is for a wife. Men play an important role in supporting couples' reproductive health needs, often influencing both the effective use of a contraceptive method and the degree of a couple's satisfaction with a chosen method (50). So involving men in family planning increases their awareness, acceptance and support to their wife's needs, choices and rights. In terms of contraception it means encouraging them to give more support to their wives.

\section{Rationale}

As discussed earlier Pakistan is the seventh populous country of the world with an annual growth rate of 2.6\% (1). Population policy of Pakistan has an ambitious goal of curtailing growth to $1.05 \%$ up till the year 2005 (51). Considering the age structure of Pakistan where 55.8\% of population belongs to young age group (2), it becomes essential to know the contraceptive use pattern especially in young women. To the best of our knowledge there is a dearth of information regarding the understanding of why women prefer one method of contraceptive over other. Young women need to practice effective but reversible contraception for which hormonal contraceptives are suitable. However evidence suggests that this is not the case and commonly used methods are withdrawal and condoms The Pakistan Reproductive Health and Family Planning survey of Pakistan (PRHFPS 2000-01) has revealed that non-hormonal contraceptive use is more popular among the women of Pakistan and a quarter of all contraceptive users are sterilized (14). It is also known that pregnancy rate is higher in women who use non-hormonal methods over a period of one year as compared to those women who use hormonal methods (8). The purpose of this study was to assess the factors affecting the choices of women who opt for a hormonal or a non-hormonal method.

\section{Objectives}

- To determine the proportion of women using hormonal and non-hormonal contraceptive methods among modern contraceptive users.

- To determine factors associated with hormonal and non hormonal contraceptive methods use.

\section{Methodology}

The project was conducted as a clinic based cross sectional survey.

\section{Study Setting}

Karachi, both Pakistan's and the province of Sindh's biggest city is growing at the rate of $6 \%$ annually which is twice Pakistan's national average, which itself suffers highest population growth rates in the world (3). The RHS centers are the major component of Pakistan's population welfare programme (52). There are a total 106 RHS-centers in Pakistan with 28 in Sindh (52). Of these 28 centers, we selected four centers in Karachi with the highest client load. These are managed by hospitals management committee but are staffed, equipped and managed by provincial population welfare department (52).

The family planning centers from where the subjects were selected with prior permission were

- Reproductive Health Services (RHS)-A center, JPMC 
- RHS-A center, Civil Hospital

- RHS-A center, Abbasi Shaheed City Government Hospital

- RHS-A center, Sindh Government Hospital, North Karachi

These clinics are located in four different areas of the city covering lower, middle and high socio economic status of women. Similar contraceptives are provided to women in these four centers. In all these centers women are offered cash incentives for undergoing tubal ligation. All the contraceptives are provided on minimal charges. Since our sample size was 1100 subjects, we interviewed exactly one-fourth subjects i.e. 275 women from each of four centers.

\section{Study Design}

Cross sectional study conducted on women of 15-49 years of age who were continuously and consistently using a modern contraceptive method for at least last three months, were selected from four family planning centers located in four hospitals of Karachi from July 2003 to September 2003.

\section{Sample Size}

For our first objective:

Percentage of hormonal users in the country is $20.0 \%$ (Reference PRDHS, 2000-01)

Using two sided test, prevalence of $20 \%$, and an error limit of $2.5 \%$,

$$
\mathrm{n}=\mathrm{Z}_{\infty / 2} \mathrm{p} \mathrm{q} / \mathrm{B}^{2}=(1.96)^{2}(0.20)(0.80) /(0.025)^{2}=984
$$

By adding $10 \%$ for non response, sample size came out to be 1082 .

For our second study objective:

With Epi-info (version 6.04), using unmatched case design with a ratio of 1:4 (considering 20\% hormonal method users against $80 \%$ non hormonal method users) (same reference as above), odds ratio of 2.0 , we calculated sample sizes from lowest prevalence of $20 \%$ to highest of $80 \%$.

\begin{tabular}{|l|l|l|l|l|l|l|l|}
\hline Prevalence $(\mathrm{p})=$ & $20 \%$ & $30 \%$ & $40 \%$ & $50 \%$ & $60 \%$ & $70 \%$ & $80 \%$ \\
\hline Sample size $(\mathrm{n})=$ & 599 & 482 & 446 & 454 & 499 & 600 & 829 \\
\hline
\end{tabular}

So we considered a sample size of 1100 women (because 1082 is the sample size with above mentioned formula calculation) that would cover the sample size obtained for our second objective as well.

\section{Selection of subjects \\ Definitions}

Modern contraceptive: Modern contraceptives are defined here as oral pills, injectables, Norplant, male condoms, tubal ligation and IUD (copper T)

Hormonal method user: A woman using oral pills, injectables, Norplant for at least last three months continuously and consistently

Non-hormonal method user: A woman using male condoms, or IUD (copper T) for at least last three months continuously and consistently. Women with tubal ligation were included as subjects only when they had the procedure during last three months but not less than a week.

\section{Sampling technique}

The women were selected by convenient sampling technique i.e. each woman who is continuously and consistently using modern contraceptive for at least last three months, and coming to the clinic was eligible to be interviewed for our study after confirmation of her method use, from the clinic record.

\section{Exclusion criteria}

Women who refused to participate or those women who had language problem were excluded from the study.

\section{Study Variables}

Dependent variable

Use of hormonal and non hormonal contraceptives

\section{Independent variables}

Socio-demographic variables

Age of women

Women's age was recorded as a continuous variable as completed years. The information was confirmed through her national identity card and from clinic record when the given information had some doubt. In case of discrepancy the age that was mentioned in the identity card was used. 
Occupation of women

This was categorized into house wife or employed.

Type of occupation of women

If employed, occupation was recorded as categorical, professional workers (doctors, engineers, and teachers), skilled workers (tailoring, beautician) and non skilled workers (cleaning, washing, and cooking).

Monthly family Income

It was recorded as categorical, Rs 1,000 to Rs 5,000, Rs 5,001 to Rs 10,000 and more than Rs 10,000.

Family type

The type of family was categorized into joint or nuclear. Women's living with her in laws was a joint family whereas one living without in laws was a nuclear family.

Education of women

It was recorded as categorical, no schooling, 8 years of education, 9-10 years of education and 11 years or more of education

Education of husband

It was recorded as categorical, no schooling, 8 years of education, 9-10 years of education, 11 years of education or more and wife does not know husband's education

Reproductive variables

Number of pregnancies

The number of pregnancies a woman had was recorded as continuous variable.

Number of living children

The number of living children a woman had was recorded as continuous variable.

Number of girl children

The number of girl children women had was recorded as continuous variable.

Number of boy children

The number of boy children women had was recorded as continuous variable.

Age of youngest child

The age of youngest child was noted in completed years if child was more than a year and in months if less than a year.

Factors affecting modern contraceptive use

Previous knowledge of contraceptives

It was categorized as having knowledge of contraceptives or not before she started current use.

Source of knowledge of contraceptives

Source of knowledge of contraceptives was recorded as categorical i.e. media, health service provider (doctor, lady health visitor) or family and friends.

Husband's approval of current contraceptive use

Husband's approval was recorded as a categorical variable i.e. yes or no

Decision about family planning

It was recorded as a categorical variable by asking her whether she alone decides about choice of contraceptive or her husband alone or both of them together or someone else like her mother in law and other family members.

Health Concerns with contraception

Women were asked about their health concerns with use of method, categorized as yes or no

Convenience of current contraceptive use

Based on the perception of the user, whether she considered the method convenient or not, categorized as yes or no

Satisfaction with current contraceptive use

This was recorded as satisfied or not satisfied by the current method being used, categorized as yes or no.

\section{Data Collection}

Two data collectors were hired for the fieldwork. Each data collector was assigned the responsibility of data collection in two clinics i.e. first she completed work at one clinic and then went on to another clinic.

\section{Data analysis}

Two independent entry experts entered the data in Epi-info version 6.04 and the files were compared to validate the data entry process. SPSS version 10.0 was used to analyze the data.

\section{Statistical Analysis}

All the analyses were done using Statistical Package for Social Sciences (SPSS) version 10.0 (53). Descriptive statistics were computed for all computed variables of the study according to the type of variables. Frequencies mean and standard deviations were obtained for continuous variable while categorical variables 
Factors affecting hormonal and non hormonal contraceptive method use in women presenting to

were assessed by computing frequencies. The "age of youngest child" variable was recorded as continuous but it was categorized at the time of analysis into age of youngest child less than a year (categorized in months) and age more than a year Logistic Regression was used to identify the factors associated with Hormonal contraceptive use. Univariate logistic regression analysis was used to assess the association of independent variables with the dependent variable. Crude odds ratio (OR) and their $95 \%$ confidence interval (CI) for each variable of interest were calculated. P values were also calculated by Likelihood Ratio Test for the significance of the beta coefficients.

Multiple Logistic Regression analysis was performed to identify associated factors of hormonal contraceptive use while adjusting for other variables. Any independent variables with $p$-value $<0.25$ in the univariate analysis and the biologically meaningful variables were included in the model. Analysis was done by Purposeful Selection Method i.e. all the variable that were selected in univariate analysis were put in the model simultaneously and the variables were selected with p-value 0.05 . All the independent variables in model were assessed for significance by the $\mathrm{p}$-value $\leq 0.05$. Any variable with $\mathrm{p}>0.05$, not a confounder or interacting with any other variable and biologically not important were removed from the model to obtain a parsimonious and biologically meaningful model that best explains the phenomena of hormonal contraceptive use. The overall significance of the model was assessed with $\mathrm{G}$ statistics.

The scales of the continuous variable were checked for assumption of linearity by quartile analysis, Box Tidwell approach and higher order term (quadratic term).

Once the correct scale of the continuous variables was evaluated all the biologically plausible interaction of the independent variables were assessed with G statistics (54). In order to assess the goodness of fit of the final model Hosmer and Lemeshow Goodness-of -fit was applied.

\section{Description of study population}

\section{Results}

A total of 1100 women using modern contraceptives were interviewed from July to September 2003. Seven interviews were discarded from the analysis due to the discrepancy in the information so the results are presented on 1093 (99.4\%) women. The mean age of the respondents was 30.4 (SD 5.5) years. Approximately $62.0 \%$ of these women were educated and same percentage of their spouses was educated as well. However 9 percent of women did not know about the educational status of their husbands. Majority of these women were house wives $(84.1 \%)$. Those who were employed $(16.0 \%)$ were professional workers $(4.3 \%)$, skilled workers (5.7\%) and non-skilled workers (6.0\%). Most of these women were living in joint family system

$(64.0 \%)$. In spite of good educational background of husbands and wives nearly $59.0 \%$ of women reported having a family income of less than Rs 5000. (Table 1a)

A total of 5,176 pregnancies were reported by these women with mean of 4.7 (SD 2.2) pregnancies per woman. The mean number of living children at the time of interview was 4.1 (SD 1.8). Most of these women reported the age of youngest child as one year or more (65.6\%). (Table 1b)Of 1093 respondents $48.2 \%$ reported using hormonal methods and $51.8 \%$ using non-hormonal methods. Of those who were hormonal users $(\mathrm{n}=527)$ the most commonly used method was Norplant $(41.0 \%)$ followed by injectables $(36.0 \%)$ and pills $(23.0 \%)$. Among non-hormonal users $(\mathrm{n}=566)$ tubal ligation $(47.5 \%)$ was followed by copper $\mathrm{T}(35.0 \%)$ and condoms (17.0\%). (Table 1c)Nearly $81.0 \%$ of women had previous knowledge of methods other than the current contraceptive they were using. The source of this knowledge was from health service providers $(39.5 \%)$ and family members and friends (35.7\%). Surprisingly media was reported by a negligible number of women (6.0\%) as a source of information.

Women reported a universal approval of husbands for their contraceptive use $(93.0 \%)$ and the decision was made as a couple in most of the cases $(61.0 \%)$. However in some instances women were the sole decision maker $(20.5 \%)$. Husbands and mothers in law(10.5\% and $8.2 \%$ respectively) had lesser role as sole decision maker. Nearly all the respondents expressed their satisfaction (95.0\%) and convenience (96.0\%) with the current method they were using at the time of interview. However approximately $50.0 \%$ of women expressed health concerns related to the method they were using. Among non- hormonal users $42.7 \%$ reported health concerns most of these were related to tubal ligation (50.4\%), IUD (30.2\%) and condom (19.4\%). Regarding hormone users $50.4 \%$ reported concerns for health. Of these Norplant users were $37.0 \%$, injection users were $36.0 \%$ and pills $26.8 \%$.

\section{Univariate Analysis}

Univariate analysis is presented in three sections; sociodemographic, reproductive behavior and past and current experience with modern contraceptive. Socio-demographic variables include age of women, monthly family income, type of family, working status of respondent, and education status of respondent and spouse. In Reproductive behavior variables include number of pregnancies, number of living children, gender of living children and age of youngest child. Past and current experience with modern contraceptive variables include those related to previous knowledge of contraceptives, source of knowledge, husband's approval, 
decision making power for contraception, health concerns, satisfaction with the method, convenience with use, and side effects with a method.

The socio-demographic variables age and working status of women were significantly associated with the use of hormonal methods. With every one year increase in age, the women are 0.9 times at lesser odds of using a hormonal method as compared to a non-hormonal method (OR 0.91; 95\% CI 0.88, 0.93), also women who were using a hormonal method were 1.38 times more at odds of being a housewife as compared to nonhormonal users (OR 1.38; 95\% CI 0.99, 1.93). (Table 2a)No significant associations were found with type of family, education of respondent and education of spouse to hormonal use of contraceptives.

The reproductive behavior variables; number of pregnancies and number and gender of living children (Table $2 b$ ) were significantly associated with hormonal use of contraception. With every pregnancy, the odds of hormonal use decreased 0.76 times (OR $0.76 ; 95 \%$ CI $0.71,0.81)$. Similarly with every addition of a living child in the family the odds of hormonal use decreased 0.72 times (OR 0.72; 95\% CI 0.67, 0.77). Interestingly with every increase of a girl child in the family the women are 1.05 times more at odds of using a hormonal method (OR 1.05; 95\% CI 1.01, 1.09).Significant factors affecting knowledge of contraceptive use were previous knowledge of contraceptives, source of knowledge of methods, husband's approval of contraceptive use, and health concerns with use of contraceptive (Table 2c). Those women who have previous knowledge of contraceptives are more likely to use a contraceptive method (OR 1.42; 95\% CI 1.05, 1.93). However having this knowledge from family and friends are influencing them for lesser use of a hormonal method. (OR 0.61; $95 \%$ CI $0.43,0.85)$ Women who had health concerns were at elevated odds of using a hormonal method (OR 1.79; 95\% CI 1.41, 2.28). (Table 2c) Women who had their husband's approval for contraceptive use were less likely to be a hormonal method user (OR $0.46 ; 95 \%$ CI $0.28,0.76$ ).

Satisfaction and convenience of current contraceptive use were not significantly associated with hormonal use. In all three sections, those variables with $\mathrm{p}$-value $\leq 0.25$ or those having biological significance i.e. number of boys and girls, decision about contraceptive use and previous knowledge of contraceptives were included in the multiple logistic regression model.

\section{Multiple logistic regression analysis}

The logistic regression model included age of women, number of pregnancies, gender of living children, previous and source of knowledge of contraceptives, approval of husband in method use, health concern with method use (Table 3). Age and number of pregnancies were found to be highly correlated so number of pregnancies was removed from the final model.

After adjusting for the effect of other variables in the model, age, number of living children, husband's approval, source of knowledge and health concerns retained their significance as independent factors influencing hormonal use. For every one year increase in age of women, the odds of hormonal use decreased 0.95 times (OR $0.95 ; 95 \%$ CI $0.92,0.98$ ). Similarly with every addition of a living child in the family the odds of hormonal use decreased 0.79 times (OR $0.79 ; 95 \%$ CI $0.73,0.86$ ). Women having their husband's approval for contraceptive use are less likely to use a hormonal method (OR 0.43; 95\% CI 0.25, 0.73). Women whose source of knowledge of contraceptives is family and friends are at lesser odds of hormonal use (OR 0.64; $95 \%$ CI $0.45,0.92$ ). Women having health concerns are at elevated odds of hormonal use (OR $1.7095 \%$ CI 1.32, 2.19).

Hosmer and Lemeshow Goodness-of-fit was applied for the final model as the number of covariate patterns and sample size approximated each other. It showed good fit (df. $=8$, chi-square $=5.429, \mathrm{p}$-value $=$ $.711)$.

\section{Discussion}

The average hormonal user in our study is a young woman of 29 years of age, with an average of four pregnancies and same number of living children, who did not have her husband's approval for contraceptive use. Her existing knowledge of contraceptive use is influenced by family and friends who is against hormonal use. She is concerned about her health related to her current contraceptive method.

As compared to hormonal user the non-hormonal user is three years older, with an average of five pregnancies and four living children, who had husband's approval for her contraceptive use. Her existing knowledge of contraceptive use is influenced by family and friends which is favorable for non- hormonal use. She is less concerned about her health related to her current contraceptive method.

In addition to characteristics described above, hormonal users had more girls as compared to nonhormonal users. Though this variable was not retained in the final model but based on Univariate analysis we can speculate that gender preference can play a role in contraceptive use per se and also affect the choice of contraceptive. We assume that hormonal users prefer temporary methods so that their fertility and gender choices can be accomplished in future if desired. These results are consistent with the findings from other studies from Pakistan and Nepal. Nepal study has demonstrated that sex preferences decreases contraceptive use by $24 \%$ and increases the total fertility rate by more than $6 \%$. However this study does not discuss the 
Factors affecting hormonal and non hormonal contraceptive method use in women presenting to

preferences of opting temporary or permanent methods specifically in relation to gender and fertility choices (55). In hormonal user group most of the women were Norplant users $(41 \%)$ which is a long duration contraceptive method. In our sample Norplant users were one year older than users of pills (mean 29.5 years vs. 28.5 years respectively) and had more boys (mean 2 vs. 1.7 boys respectively). Here again the gender seems to be the factor pushing these women to use a long duration hormonal method. Other studies also support the fact that women who opted for Norplant discontinue its use because they had fewer live births and were more likely to desire additional children (56).

On the contrary non-hormonal users in our sample, who are mostly women undergone tubal ligation (47.5\%) have attained the desired family size and also desired number of sons in the family; hence would prefer for permanent or long duration methods. Data from Pakistan has revealed that the percentage of acceptors of sterilization increased over time and with increase in age and children ever born (CEB) (57). According to a review of the literature pertaining to declining fertility with age by Gray (1979), the likelihood of permanent sterility at age 40 is about $40 \%$ and at age 45 is about $80 \%$. For the remainder, above age 40 the monthly risk of pregnancy declines as ovulation becomes less frequent (58). Our study shows that more women opt for tubal ligation after they have three or more children. Same results have been reported from Bangladesh where younger women opted for birth spacing methods, while older women generally preferred sterilization (45).

Majority of women $1020(93 \%)$ reported husband's approval for contraceptive use. This was expected as they were already using a method. Only $73(6.7 \%)$ of women said that their husbands do not approve their contraceptive use. Of these women 66 percent (48/73) belonged to hormonal user group as compared to nonhormonal users (25/73). We assume that these women were using these methods without the knowledge of their husbands or may be their husbands were aware of their wife's contraceptive use but still did not approve hormonal contraceptive use. Non-hormonal users had husband's approval as majority had undergone tubal ligation which cannot be done without husband's permission in this country and also $17 \%$ of women reported condom use which is itself a male method. Studies have revealed that husbands involvement strongly affect the contraceptive use (59); couple's joint approval, discussion of family planning, and husband's desire for no more children have the strongest effect on promoting contraceptive use.

In our study source of knowledge as significant predictor is consistent with study findings elsewhere (60-62). Our Hormonal user is seen being affected by her source of previous knowledge of contraceptives particularly role of family and friends. Over the years experience in contraceptive use has shown that a number of factors govern contraceptive use and contraceptive choices for a woman or a couple. Social and religious set up also have strong correlations (63).

In our sample health service provider's role in tubal ligation (41.0\%), Norplant use (44.0\%) and pill use (45.0\%) and IUD use (37.0\%) is particularly noticeable whereas family and friends are affecting injectable use (42.0\%) and IUD use (41.0\%). Norplant, tubal ligation and IUD are health service provider dependent methods, being undertaken by trained doctors or health care professionals only. Pills and injectables need not only expert advice but also women need motivation to use these consistently. Family and friends can be a role model for them. Media did not appear to be a significant source of information in our sample. This needs to be further explored.

Hormonal users showed health concerns related to their current method they were using. Most of these concerns were with pills and injection. Studies have shown that women discontinue use when faced with breakthrough bleeding or weight gain. Additionally women have many misconcepts related to pills and injections (64). Additionally women have many misconcepts related to pills and injections (63). Since this was a cross sectional survey and we only selected those women who were using these methods for last three months and did not ask about the duration of this use beyond three months hence we cannot comment on their continuation of these methods in future or relate this to their prolonged use. Data from Pakistan has shown that women who go for tubal ligation do so after having 4-5 or more children. The recent thrust of the government of Pakistan is to promote long term temporary methods to be used by relatively younger population. Hence the proportion of users of Norplant is higher in our study sample in hormonal contraceptive users.

\section{Limitations of the study}

Our study does not represent the population of contraceptive users of Pakistan; however it does give us insight into the profile of hormonal and non-hormonal users fairly well. Also the women were enrolled from the government facilities only this may affect the contraceptive method chosen depending on the government policy and availability of the contraceptives in the centers and may not represent the true picture in the general population.

To select a method, women may not understand what hormonal or non-hormonal means but her choice of selection may have been based only on the duration of contraception which a method provided. Information on this aspect of method choice would give additional information and needs to be explored in future studies.

Further more the study centers were government run so factors like cost of contraceptives and accessibility of services could not be studied. 
Factors affecting hormonal and non hormonal contraceptive method use in women presenting to

\section{Conclusion}

The factors governing the hormonal use are age, number of pregnancies and living children. Furthermore hormonal users are concerned regarding the affect of hormones on their health.

Media has little role for dissemination of information regarding contraceptives

\section{Recommendations}

Further representative studies are needed to see the changing trend in the method choices and factors governing these choices for future policy implications. Awareness among women with regard to contraceptive use and their health concerns with contraceptive use can be effectively alleviated by utilization of existing services and by enhancing use of media. Continuous and consistent use of contraceptives is ensured only when fears and health concerns are adequately addressed.

Table 1a: Descriptive frequencies of Socio-demographic Characteristics of Modern Contraceptive Users of Karachi, July to September $2003(n=1093)$

\begin{tabular}{|c|c|c|}
\hline Variable & $\mathbf{n}$ & $\%$ \\
\hline Mean Age of women (SD) & & $30.4(5.5)$ \\
\hline \multicolumn{3}{|l|}{ Occupation } \\
\hline Housewife & 919 & 84.1 \\
\hline Employed & 174 & 15.9 \\
\hline \multicolumn{3}{|l|}{ Type of employment } \\
\hline Professional worker & 47 & 43 \\
\hline Skilled workers & $\begin{array}{l}41 \\
62\end{array}$ & 5.7 \\
\hline Non skilled workers & 65 & 5.9 \\
\hline \multirow{2}{*}{\multicolumn{3}{|c|}{$\begin{array}{c}\text { Monthly Family Income (Pak Rupees) } \\
>10,000\end{array}$}} \\
\hline & & \\
\hline $5,001-10,000$ & 77 & 66 \\
\hline $1,000-5,000$ & 371 & 33.9 \\
\hline Family Structure & 650 & 59.5 \\
\hline Nuclear & 303 & 360 \\
\hline Joint & 700 & 64.0 \\
\hline \multicolumn{3}{|l|}{ Education of respondent } \\
\hline No schooling & 416 & 38.1 \\
\hline$\leq 8$ years of education & 237 & 21.7 \\
\hline years of education & 265 & 24.2 \\
\hline 11-12 years of education or more & 175 & 16.0 \\
\hline \multicolumn{3}{|l|}{ Education of spouse } \\
\hline No schooling & 315 & 288 \\
\hline$\leq 8$ years of education & 195 & 17.8 \\
\hline 9-10 years of education & 223 & 20.4 \\
\hline 11-12 years of education or more & 260 & 23.8 \\
\hline Wife does not know his education & 100 & 9.1 \\
\hline
\end{tabular}

SD Standard deviation

Table 1b: Reproductive History of Modern Contraceptive Users, Karachi, July to September 2003 ( $\mathrm{n}=1093$ )

\begin{tabular}{|l|c|c|}
\hline \multicolumn{1}{|c|}{ Variable } & $\mathbf{n}$ & mean (SD) \\
\hline Number of pregnancies & 5176 & $4.7(2.2)$ \\
Number of living children & 4558 & $4.1(1.9)$ \\
Number of boys & 2492 & $2.8(1.9)$ \\
Number of girls & 2066 & $3.2(2.9)$ \\
Age of youngest child & & $\%$ \\
Age less than one year & 376 & 34.4 \\
Age one year or more & 717 & 65.6 \\
\hline
\end{tabular}


Factors affecting hormonal and non hormonal contraceptive method use in women presenting to Table 1c: Descriptive frequencies of factors affecting Modern Contraceptive Use, Karachi, July to September

\begin{tabular}{|c|c|c|}
\hline Variable & $\mathbf{n}$ & $\%$ \\
\hline \multicolumn{3}{|l|}{ Current contraceptive use } \\
\hline Hormonal Methods & 527 & 48.2 \\
\hline Oral Pills & 121 & 11.1 \\
\hline Injectables & 190 & 17.4 \\
\hline Norplant & 216 & 19.8 \\
\hline Non Hormonal Methods & 566 & 51.8 \\
\hline Intra uterine device & 199 & 18.2 \\
\hline Tubal ligation & 269 & 24.6 \\
\hline Male Condoms & 98 & 9.0 \\
\hline \multicolumn{3}{|l|}{ Previous knowledge of contraceptives } \\
\hline Yes & 888 & 81.2 \\
\hline No & 205 & 18.8 \\
\hline Source of previous knowledge & 66 & 6.0 \\
\hline Media & 390 & 35.7 \\
\hline Family and friends & 432 & 39.5 \\
\hline $\begin{array}{l}\text { Health service provider } \\
\text { No knowledge }\end{array}$ & 205 & 18.8 \\
\hline Husband's approval for current contraceptive use & 1020 & 93.3 \\
\hline Yes & 73 & 6.7 \\
\hline No & 115 & 10.5 \\
\hline Decision making regarding current contraceptive use & 224 & 20.5 \\
\hline Husband & 664 & 60.8 \\
\hline Wife & 90 & 8.2 \\
\hline \multicolumn{3}{|l|}{ Couple } \\
\hline Mother in law and other family members & 544 & 49.8 \\
\hline $\begin{array}{l}\text { Health concerns with current contraceptive use } \\
\text { Yes }\end{array}$ & 549 & 50.2 \\
\hline No & 1035 & 94.7 \\
\hline Satisfaction with current method use & 58 & 5.3 \\
\hline Yes & 1048 & 95.9 \\
\hline No & 45 & 4.1 \\
\hline \multicolumn{3}{|l|}{ Convenience with current method use } \\
\hline Yes & 552 & 50.5 \\
\hline No & 541 & 49.5 \\
\hline
\end{tabular}

Table 2a. Univariate analysis showing the association of Socio-demographic factors with hormonal use,

Karachi, July to September $2003(n=1093)$

\begin{tabular}{|c|c|c|c|c|}
\hline Variable & $\begin{array}{c}\text { Hormonal } \\
\text { usern }=527 \text { n (\%) }\end{array}$ & $\begin{array}{c}\text { Non-hormonal user } \\
n=566 \mathrm{n}(\%)\end{array}$ & Odds ratio & p-value \\
\hline $\begin{array}{l}\text { Mean age of women (SD) } \\
\text { Monthly Family Income (Pak Rupees) } \\
>11,000 \\
1,000-5,000 \\
5,001-11,000 \\
\text { Nuclear } \\
\text { Joint } \\
\text { Type of family } \\
\text { Working status } \\
\text { Employed } \\
\text { Housewife } \\
\text { Education of respondent } \\
\text { No schooling } \\
\leq 8 \text { years of education } \\
\text { 9-10 years of education } \\
11-12 \text { years of education or more } \\
\text { Education of spouse } \\
\text { No schooling } \\
\leq 8 \text { years of education } \\
\text { 9-10 years of education } \\
\geq 11 \text { years of education } \\
\text { Wife does not know his } \\
\text { education }\end{array}$ & $\begin{array}{l}29.1(4.8) \\
30(5.7) \\
324(61.5) \\
173(32.8) \\
203(38.5) \\
324(61.5) \\
72(13.7) \\
455(86.3) \\
196(37.2) \\
121(23.0) \\
126(23.9) \\
84(15.9) \\
147(27.9) \\
92(17.5) \\
106(20.1) \\
133(25.2) \\
49(9.3)\end{array}$ & $\begin{array}{l}31.8(5.6) \\
42(7.4) \\
326(57.6) \\
198(35.0) \\
190(33.6) \\
376(66.4) \\
102(18.0) \\
464(82.0) \\
\\
220(38.9) \\
116(20.5) \\
139(24.6) \\
91(16.1) \\
168(29.7) \\
103(18.2) \\
117(20.7) \\
127(22.4) \\
51(9.0)\end{array}$ & $\begin{array}{c}0.91(0.88,0.93) \\
1.00 \\
1.40(0.85,2.29) \\
1.20(0.72,2.01) \\
\\
1.00 \\
1.23(0.96,1.57) \\
1.00 \\
1.38(0.99,1.93) \\
1.00 \\
1.18(0.85,1.62) \\
1.01(0.74,1.37) \\
1.02(0.72,1.45) \\
1.00 \\
1.03(0.72,1.45) \\
1.04(0.74,1.47) \\
1.20(0.86,1.67) \\
1.10(0.70,1.73)\end{array}$ & $\begin{array}{c}<0.01 * \\
0.27\end{array}$ \\
\hline
\end{tabular}


Factors affecting hormonal and non hormonal contraceptive method use in women presenting to

Table 2b. Univariate analysis showing the association of Reproductive factors with hormonal use, Karachi, July to September $2003(\mathrm{n}=1093)$

\begin{tabular}{|c|c|c|c|c|}
\hline Variable & $\begin{array}{c}\text { Hormonal user } \\
\mathbf{n}=\mathbf{5 2 7}\end{array}$ & $\begin{array}{c}\text { Non-hormonal } \\
\text { user } \\
n=566\end{array}$ & Odds ratio & p-value \\
\hline $\begin{array}{l}\text { Number of living children } \\
\text { Number of pregnancies } \\
\text { Number of boys } \\
\text { Number of girls }\end{array}$ & $\begin{array}{l}\text { Mean }(\mathrm{SD}) \\
3.6(1.5) \\
4.1(1.8) \\
2.8(2.1) \\
3.4(3.1)\end{array}$ & $\begin{array}{c}\text { Mean (SD) } \\
4.7(2.0) \\
5.3(2.4) \\
2.9(1.6) \\
2.9(2.5)\end{array}$ & $\begin{array}{l}0.72(0.67,0.77) \\
0.76(0.71,0.81) \\
0.96(0.90,1.02) \\
1.05(1.01,1.09)\end{array}$ & $\begin{array}{c}<0.01 * \\
<0.01 * \\
0.22 \\
0.01 *\end{array}$ \\
\hline $\begin{array}{l}\text { Age of youngest child } \\
\text { Age less than one year } \\
\text { Age one year or more }\end{array}$ & $\begin{array}{c}\mathrm{n}(\%) \\
177(33.6) \\
350(66.4)\end{array}$ & $\begin{array}{c}\mathrm{n}(\%) \\
199(35.2) \\
367(64.8)\end{array}$ & $\begin{array}{c}1.00 \\
1.07(0.83,1.37) \\
\end{array}$ & 0.59 \\
\hline
\end{tabular}

*significant

Table 2c. Univariate analysis showing the possible association for variables evaluated for their association with hormonal contraceptive use, Karachi, July to September 2003 ( $\mathrm{n}=1093$ )

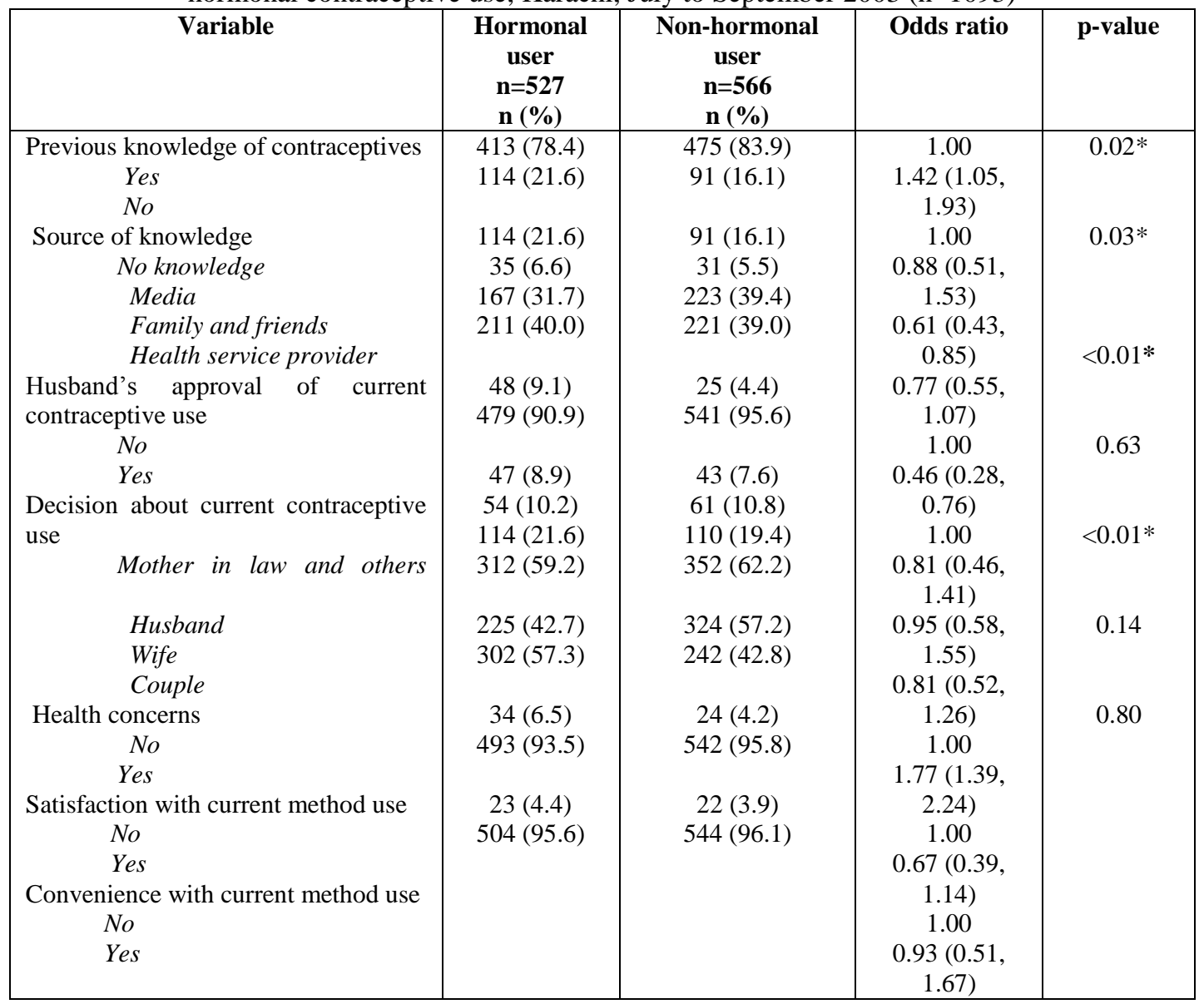

* Significant 
Factors affecting hormonal and non hormonal contraceptive method use in women presenting to

Table 3. Multiple Logistic Regression Analysis of factors associated with Hormonal Contraceptive Use among Modern Contraceptive Users, Karachi, Pakistan, July to September 2003 ( $\mathrm{n}=1093$ )

\begin{tabular}{|l|c|c|c|c|}
\hline \multicolumn{1}{|c|}{ Variables } & \multirow{2}{*}{ Sig. } & Adjusted & \multicolumn{2}{c|}{ 95\% C.I. } \\
\cline { 3 - 5 } & & OR & Lower & Upper \\
\hline $\begin{array}{l}\text { Age (completed years)* } \\
\text { Number of living children* } \\
\text { Approval of husband for current } \\
\text { use }\end{array}$ & $<0.01$ & 0.95 & 0.92 & 0.98 \\
$\quad$ & & 0.79 & 0.73 & 0.86 \\
$\quad$ Yes & $<0.01$ & 1.00 & & \\
$\quad$ No & 0.43 & 0.25 & 0.73 \\
Source of previous knowledge & $\mathbf{0 . 0 4}$ & 1.00 & & \\
$\quad$ No knowledge & 0.82 & 1.07 & 0.58 & 1.94 \\
$\quad \begin{array}{l}\text { Media } \\
\text { Family and friends }\end{array}$ & 0.01 & 0.64 & 0.45 & 0.92 \\
$\quad$ Health service provider & 0.52 & 0.89 & 0.62 & 1.27 \\
Health concern & & 1.00 & & \\
$\quad$ Yes & $<0.01$ & 1.70 & 1.32 & 2.19 \\
$\quad$ No & & & & \\
\hline
\end{tabular}

*Continuous variables

-2 Log Likelihood 1377

Goodness of fit $\chi^{2} 5.4$, df 8 , p -value 0.71

\section{References}

[1]. Fikree FF. Reproductive health in Pakistan: evidence and future directions. J Pak Med Assoc 2002;52(1):34-41.

[2]. CIA. World Facts Index. In: The CIA World Fact Book, US Department of State; 2005. p. Area Handbook of the US Library of Congress.

[3]. Congress ULo. Population of Pakistan: Federal Research Division of the Library of Congress; 2004.

[4]. Ali W. Government urged to work on cutting maternal mortality. Daily Times 2005 05-07-05;Sect. 7-18.

[5]. Shen C, Williamson JB. Maternal mortality, women's status, and economic dependency in less developed countries: a cross-national analysis. Soc Sci Med 1999;49(2):197-214.

[6]. Kibirige JS. Population growth, poverty and health. Soc Sci Med 1997;45(2):247-59.

[7]. Latif KR. Textbook of Gynaecology. Third ed. Lahore; 2000.

[8]. Hatcher AR, Ward R, Blackburn R, Geller SJ, Shelton DJ. The essentials of Contraceptive Technology, A Handbook for clinic staff. Baltimore, United States: Population Information Programme, John Hopkins University School of Public Health; 1997.

[9]. What makes a contraceptive acceptable?: UNFPA, UNDP, WHO, World Bank; 1997.

[10]. Warren M. Better safe than sorry. New Int 1987(176):22.

[11]. USAID. Unmet need for contraception. Population Briefs 1998.

[12]. FHI. Unmet need affects millions: Family Health International; 1999.

[13]. Hastings F. World Contraceptive Use and Effectiveness. In: Quality of Life in the Global Century: Physician's desk reference 2003; 2005.

[14]. Abdul H, Mehboob S, Faateh u. Pakistan Reproductive Health and Family Planning Survey, 2000-01 - Preliminary Report. Islamabad: National Institute of Population Studies; 2001 July 2001.

[15]. Abdul H, John C, Mansoor ul Hassan B. Pakistan Fertility and Family Planning Survey 1996-97: National Institue of Population Studies, London School of Hygiene and tropical Medicine; 1999.

[16]. Paraskevopoulou E, Raymond L, Oakeshott P. Factors influencing contraceptive use in Tehran. Fam Pract 2003;20(4):493.

[17]. Davis KR, Weller SC. The effectiveness of condoms in reducing heterosexual transmission of HIV. Fam Plann Perspect 1999;31(6):272-9.

[18]. CDC. Latex condoms and sexually transmitted diseases-Prevention messages. Atlanta, GA: National center for HIV, STD \& TB prevention, Centers for Disease Control.

[19]. Harlap S, Kost K, Darroch FJ. Preventing pregnancy, Protecting health: A New Look at Birth Control choices in the United states. Allan Guttmacher Institute 1991(92).

[20]. Trussell J, Vaughan B, Stanford J. Are all contraceptive failures unintended pregnancies? Evidence from the 1995 National Survey of Family Growth. Fam Plann Perspect 1999;31(5):246-7, 260.

[21]. Hufnagel MV. No More Hysterectomies. New York: Penguin; 1989.

[22]. Hargrove JT, Abraham GE. Endocrine profile of patients with post-tubal-ligation syndrome. J Reprod Med 1981;26(7):359-62.

[23]. The TCu380A, TCu220C, multiload 250 and Nova T IUDS at 3,5 and 7 years of use--results from three randomized multicentre trials. World Health Organization. Special Programme of Research, Development and Research Training in Human Reproduction: Task Force on the Safety and Efficacy of Fertility Regulating Methods. Contraception 1990;42(2):141-58.

[24]. IUDs--an update. Popul Rep B 1995(6):1-35.

[25]. Hillis SD, Marchbanks PA, Tylor LR, Peterson HB. Poststerilization regret: findings from the United States Collaborative Review of Sterilization. Obstet Gynecol 1999;93(6):889-95.

[26]. Schmidt JE, Hillis SD, Marchbanks PA, Jeng G, Peterson HB. Requesting information about and obtaining reversal after tubal sterilization: findings from the U.S. Collaborative Review of Sterilization. Fertil Steril 2000;74(5):892-8.

[27]. Hubacher D, Lara-Ricalde R, Taylor DJ, Guerra-Infante F, Guzman-Rodriguez R. Use of copper intrauterine devices and the risk of tubal infertility among nulligravid women. N Engl J Med 2001;345(8):561-7.

[28]. Rosenberg MJ, Waugh MS, Long S. Unintended pregnancies and use, misuse and discontinuation of oral contraceptives. J Reprod Med 1995;40(5):355-60.

[29]. Cifuentes R, Torres LA. [Norplant: an effective option for adolescent women. Subdermal implant contraception in adolescent women. Preliminary findings in 174 cases]. Profamilia 1995;12(25):73-7. 
Factors affecting hormonal and non hormonal contraceptive method use in women presenting to

[30]. Hatcher R, Trussel J, Stewart F, Cates W, Stewart G, Guest F, et al. Contraceptive Technology. 16 ed. New York: Irvington publishers; 1994.

[31]. Sulak PJ, Scow RD, Preece C, Riggs MW, Kuehl TJ. Hormone withdrawal symptoms in oral contraceptive users. Obstet Gynecol 2000;95(2):261-6.

[32]. Rockville M. Guidance for industry: combined oral contraceptives — labeling for healthcare providers and patients. Draft guidance. In: Food and Drug Administration, Center for Drug Evaluation and Research,; 2000.

[33]. Moreno V, Bosch FX, Munoz N, Meijer CJ, Shah KV, Walboomers JM, et al. Effect of oral contraceptives on risk of cervical cancer in women with human papillomavirus infection: the IARC multicentric case-control study. Lancet 2002;359(9312):1085-92.

[34]. Fraser IS. Long acting injectable hormonal contraceptives. Clin Reprod Fertil 1982;1(1):67-88.

[35]. Croxatto H. Progestagen Implant. International Planned Parenthood Federation Med Bull 2000:1-3.

[36]. Kang W, Tan KH. Implant contraception in Singaporean women: one decade of experience in KK Women's and Children's Hospital. Singapore Med J 2004;45(10):482-6.

[37]. Chompootaweep S, Kochagarn E, Sirisumpan S, Tang-usaha J, Theppitaksak B, Dusitsin N. Effectiveness of Norplant implants among Thai women in Bangkok. Contraception 1996; 53(1):33-6.

[38]. Zheng SR, Zheng HM, Qian SZ, Sang GW, Kaper RF. A randomized multicenter study comparing the efficacy and bleeding pattern of a single-rod (Implanon) and a six-capsule (Norplant) hormonal contraceptive implant. Contraception 1999;60(1):1-8.

[39]. Sivin I, Mishell DR, Jr., Darney P, Wan L, Christ M. Levonorgestrel capsule implants in the United States: a 5-year study. Obstet Gynecol 1998;92(3):337-44.

[40]. Oloto E, Bromham D, Walling M. Treatment of menstrual side effects and non-menstrual side effects of Norplant: recommendationsof expert group. Br J Fam Plann 1995; 21:3-5.

[41]. Norplant. Biomedicine, Population Council 2005 1st Feb 2005.

[42]. ehan N, Inayatullah A, Chaudhary I. Norplant: users' perspective in Pakistan. Adv Contracept 1999;15(2):95-107.

[43]. Barnett B. Clients prefer method choices. Network 1998;19(1):14-8.

[44]. Barnett B. Life stages affect method use. Network 1995;15(3):14-7.

[45]. Bangladesh: modern methods are well known but not widely used. Prog Hum Reprod Res 1991(19):1, 6-7.

[46]. Sandra GG, Snow R, Aitken I. Preferences for Contraceptive Attributes: Voices of Women in Ciudad Juarez, Mexico. International Family Planning Perspectives 1997; 23(2):52-58.

[47]. Vitzthum VJ, Ringheim K. Hormonal contraception and physiology: a research-based theory of discontinuation due to side effects. Stud Fam Plann 2005; 36(1):13-32.

[48]. Goretzlehner G, Carol W, Kohler G. [Hormonal contraception--side effects and surgical aspects (author's transl)]. Zentralbl Chir 1980; 105(24):1601-16.

[49]. The effect of quality of care on contraceptive efficacy. IPPF Med Bull 1994;28(4):2-3.

[50]. Herndon N. Men influence contraceptive use. Network 1998;18(3):13.

[51]. Asian and Pacific population targets. Asian Pac Popul Programme News 1982;11(4):22-4.

[52]. Brief for Pakistan official webpage, Ministry of Population Welfare. Islamabad; 2005 10-26-2005.

[53]. Statistical Package for Social Sciences (SPSS). In. 10.0 ed. Chicago, IL; 2000.

[54]. Hosmer WD, Lemeshow S. Applied Logisitic Regression. New York: John Wiley \& Sons; 1989.

[55]. Leone T, Matthews Z, Dalla Zuanna G. Impact and determinants of sex preference in Nepal. Int Fam Plan Perspect 2003;29(2):6975.

[56]. Krueger SL, Dunson TR, Amatya RN. Norplant contraceptive acceptability among women in five Asian countries. Contraception 1994;50(4):349-61.

[57]. Bhatti MH. Correlates of choice of contraceptive methods in Pakistan. Pak Dev Rev 1995;34(4 Pt. III):889-98.

[58]. Guillebaud J. Contraception for the older woman. J Obstet Gynaecol 1985;5 Suppl 2:S70-7.

[59]. Casterline JB, Sathar ZA, ul Haque M. Obstacles to contraceptive use in Pakistan: a study in Punjab. Stud Fam Plann 2001;32(2):95-110.

[60]. Mahmood N, Ringheim K. Factors affecting contraceptive use in Pakistan. Pak Dev Rev 1996;35(1):1-22.

[61]. Konje JC, Oladini F, Otolorin EO, Ladipo OO. Factors determining the choice of contraceptive methods at the Family Planning Clinic, University College Hospital, Ibadan, Nigeria. Br J Fam Plann 1998; 24(3):107-10.

[62]. Tehrani FR, Farahani FK, Hashemi M. Factors influencing contraceptive use in Tehran. Fam Pract 2001; 18(2):204-8.

[63]. Sarah S, Ahmad IM. Trials of Improved Practices on Male Involvement in Family in Pakistan. Islamabad: Department of Community Health Sciences, The Aga Khan University, Karachi, Pakistan; 2001.

[64]. Nasra S, Makhdoom AS. From non-use to use: Prospects of contraceptive adoption. In Fertility in Pakistan: A review of findings from the Pakistan Fertility Survey. Netherlands: International Statistical Institute; 1984. 